\title{
EFFECT OF GEOMETRICAL PARAMETERS ON BUCKLING STRENGTH OF MILD STEEL COLUMN FOR VARYING WALL THICKNESS
}

\author{
Sajal Kumar'1, Sudhir Kumar Kashyap ${ }^{2}$ \\ ${ }^{1}$ Post Graduate Scholar, B.I.T Sindri Dhanbad-828123 \\ ${ }^{2}$ Senior Principal Scientist, CSIR-CIMFR, Barwa Road, Dhanbad -826015
}

\begin{abstract}
Buckling of a column depends on the various geometrical parameters and material. Buckling strength mainly depends on the crushing strength, area of cross section length and the radius of gyration. For the mild steel hollow columns having length and outer diameter same and different wall thickness, buckling load for fix-fix end condition decreases as the radius of gyration increases. It has also been observed that with increment in slenderness ratio (l/k) the wall thickness and buckling load increases. Additionally, buckling load decreases as the ratio of inner to outer diameter increases.
\end{abstract}

\section{INTRODUCTION}

As per literature review it has been observed that the bending behavior of columns depends on different parameters like the end condition, geometrical imperfection and the size $e^{[1,2,3,4,5,6,7,8] .}$. Also, the effect of geometrical parameters on the buckling of different shaped ( e.g. rectangular ,square, circular, conical) columns ${ }^{9,10,11,12]}$ have been studied. In this paper the effort has been made to analyze the buckling behavior of hollow mild steel column fix-fix end condition. Figure 1 shows the Image of mild steel columnswhose outer diameter are fixing and cross sectional areas vary keeping the length constant. An experimentation setup has been done with mild steel columns having outer diameter $60 \mathrm{~mm}$; length $1520 \mathrm{~mm}$ and varying wall thickness like $1.6 \mathrm{~mm}, 1.8 \mathrm{~mm}, 2.3 \mathrm{~mm}, 2.9 \mathrm{~mm}$ and $3.3 \mathrm{~mm}$.

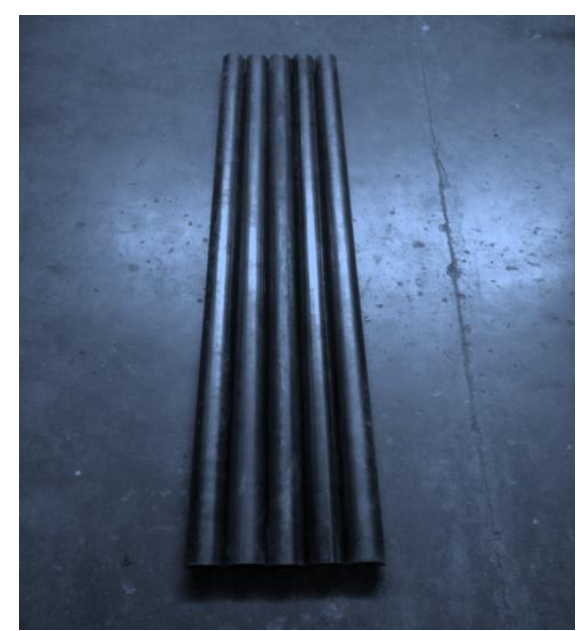

Fig 1: Hollow mild steel column)

The chemical composition of each column is shown in table. Table 1 shows the different percentage of carbon, silicon and manganese. Carbon percentage varies from 0.0418 to 0.0574 in each column.
Table 1: Chemical composition of given mild steel column

\begin{tabular}{|l|l|l|l|}
\hline Column no & $\mathrm{C} \%$ & $\mathrm{Si} \%$ & $\mathrm{Mn} \%$ \\
\hline 1 & 0.0418 & 0.0224 & 0.203 \\
\hline 2 & 0.0496 & 0.0205 & 0.215 \\
\hline 3 & 0.0514 & 0.0234 & 0.254 \\
\hline 4 & 0.0574 & 0.0214 & 0.463 \\
\hline 5 & 0.0485 & 0.0283 & 0.227 \\
\hline
\end{tabular}

\section{EXPERIMENTATION}

To find the experimental value of buckling load the experimentation is done the on the 100 ton vertical compression testing machine Figure 2. During the experimentation we measure the load of buckling for the different column. The value obtained for buckling load for different wall thicknesses have been shown in table 2 .

Specification of 100 Ton Vertical Compression Testing Machine:

Capacity-100 Tones

CMRI/SDT43/CTM-01

Voltage-440

Phase-3

Cycles-50

Type-7IN48DCJ

Number-E 6/1015 


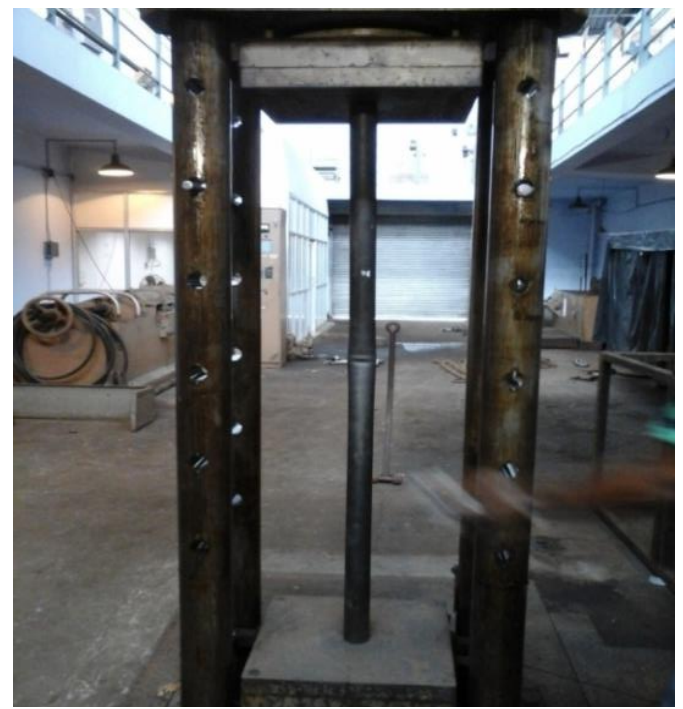

Fig 2: Experimental setup

Table 2: Columns and their wall thickness

\begin{tabular}{|l|l|l|}
\hline Column no & $\begin{array}{l}\text { Wall } \\
\text { thickness } \\
\text { inmm. }\end{array}$ & $\begin{array}{l}\text { Experimental } \\
\text { buckling } \\
\text { load }\end{array}$ \\
\hline 1. & 1.6 & 6 \\
\hline 2. & 1.8 & 7.5 \\
\hline 3. & 2.3 & 11.5 \\
\hline 4. & 2.9 & 14.7 \\
\hline 5. & 3.3 & 18 \\
\hline
\end{tabular}

\section{IMPACT OF GEOMETICAL PARAMETERS ON AXIAL COMPRESSIVE BEHAVIOUR}

As it has been seen in the literature reviews that the compressive behavior of a member very much depends on the geometrical parameter where as buckling load depends on the moment of inertia and length. The various geometrical parameters of the columns are shown in the table 3 given below.

Table 3: Various geometrical parameters of columns)

\begin{tabular}{|l|l|l|l|l|l|}
\hline $\begin{array}{l}\mathrm{C} \\
\text { ol } \\
\mathrm{u} \\
\mathrm{m} \\
\mathrm{n} \\
\text { no }\end{array}$ & $\begin{array}{l}\text { thick } \\
\text { ness }\end{array}$ & $\begin{array}{l}\text { Radiu of } \\
\text { gyrati } \\
\text { on (k) } \\
\mathrm{mm}\end{array}$ & $\begin{array}{l}\text { Slende } \\
\text { rness } \\
\text { ratio } \\
(\mathrm{L} / \mathrm{k})\end{array}$ & $\begin{array}{l}\text { Area of } \\
\text { cross } \\
\text { section } \\
\left(\mathrm{mm}^{2}\right)\end{array}$ & $\begin{array}{l}\text { Ratio } \\
\text { of } \\
\text { inner } \\
\text { to the } \\
\text { outer } \\
\text { radius }\end{array}$ \\
\hline 1. & 1.6 & 20.65 & 36.80 & 293.40 & 0.947 \\
\hline 2. & 1.8 & 20.59 & 36.91 & 328.94 & 0.940 \\
\hline 3. & 2.3 & 20.41 & 37.23 & 416.70 & 0.923 \\
\hline 4. & 2.9 & 20.36 & 37.32 & 519.95 & 0.900 \\
\hline 5. & 3.3 & 20.08 & 37.84 & 587.53 & 0.890 \\
\hline
\end{tabular}

This table shows that as wall thickness of the pipes increase then radius of gyration decrease and slenderness ratio $(1 / \mathrm{k})$ increases. Both radius of gyration and slenderness ratio affect the buckling load of the pipe or column as shown in the curves in figure $3 \mathrm{~A} \& 3 \mathrm{~B}$.

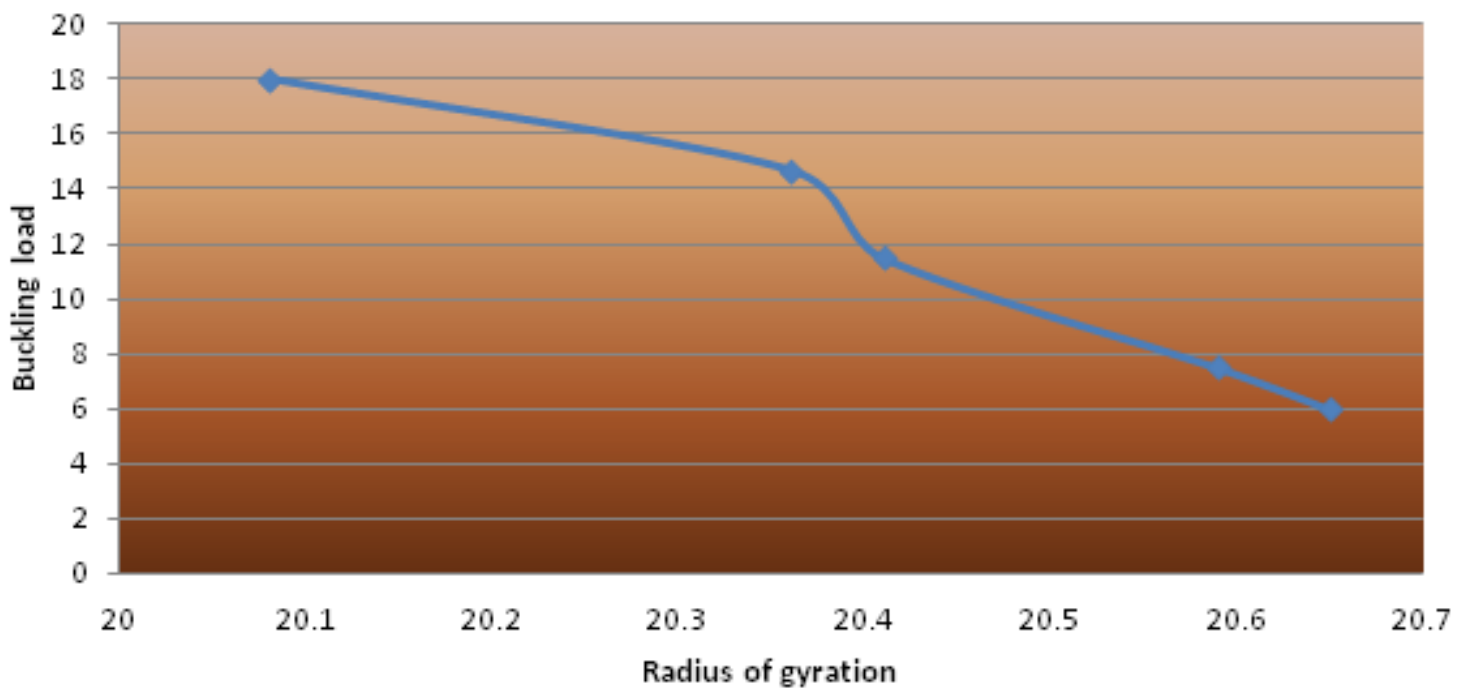

Fig 3A: Effect of radius of gyration on the buckling load

From the figure $3 \mathrm{~A}$ it is observed that as the radius of gyration increases the buckling load decreases. For the column having wall thickness from 1.6.to $1.8 \mathrm{~mm}$ the rate of increase of buckling load with decrease of radius of gyration is $535 \%$. For the columns having thickness of 1.8 to $2.3 \mathrm{~mm}$ the rate of increase of buckling load with decrease of radius of gyration is $2222.2 \%$.Again the column having thickness of 2.3 to 2.9 the rate of increase of buckling load with decrease of radius of gyration is $6400 \%$ i.e very high rate of increase of buckling load with decrease of radius of gyration. For the wall thickness 2.9 to 3.3 buckling load increase with rate of $1178.5 \%$.Therefore it can be concluded that when the wall thickness varies from 2.3 to 2.9 buckling strength of the column increases with a very high rate. 


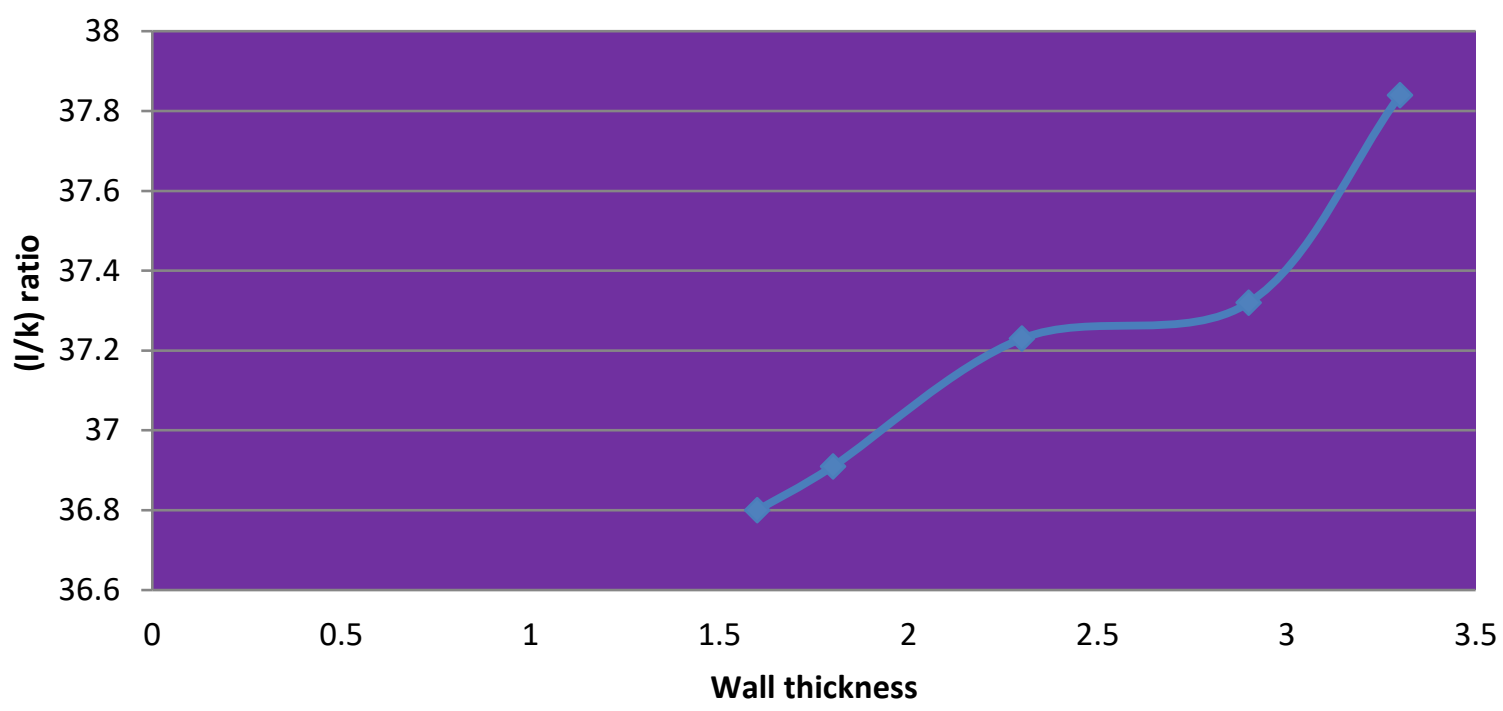

Fig 3B: Graph of Slenderness ratio to the wall thickness of the column

It is observed that with increase in wall thickness the $(1 / \mathrm{k})$ ratio also increases .It can be seen in figure $3 \mathrm{~B}$ that as wall thickness varies from 1.6 to 1.8 the rate of increase of $(1 / \mathrm{k})$ ratio is $55 \%$. When thickness increase from 1.8 to 2.3 the increment rate is $65 \%$ again when the thickness from 2.3 to
2.9 increment of $15 \%$ and when thickness increase from 2.9 to 3.3 the rate of increment is $130 \%$. Therefore as the wall thickness varies from 2.3 to 2.9 the rate of increase of slenderness ratio is comparatively lower and as thickness varies from 2.9 to 3.3 comparatively higher.

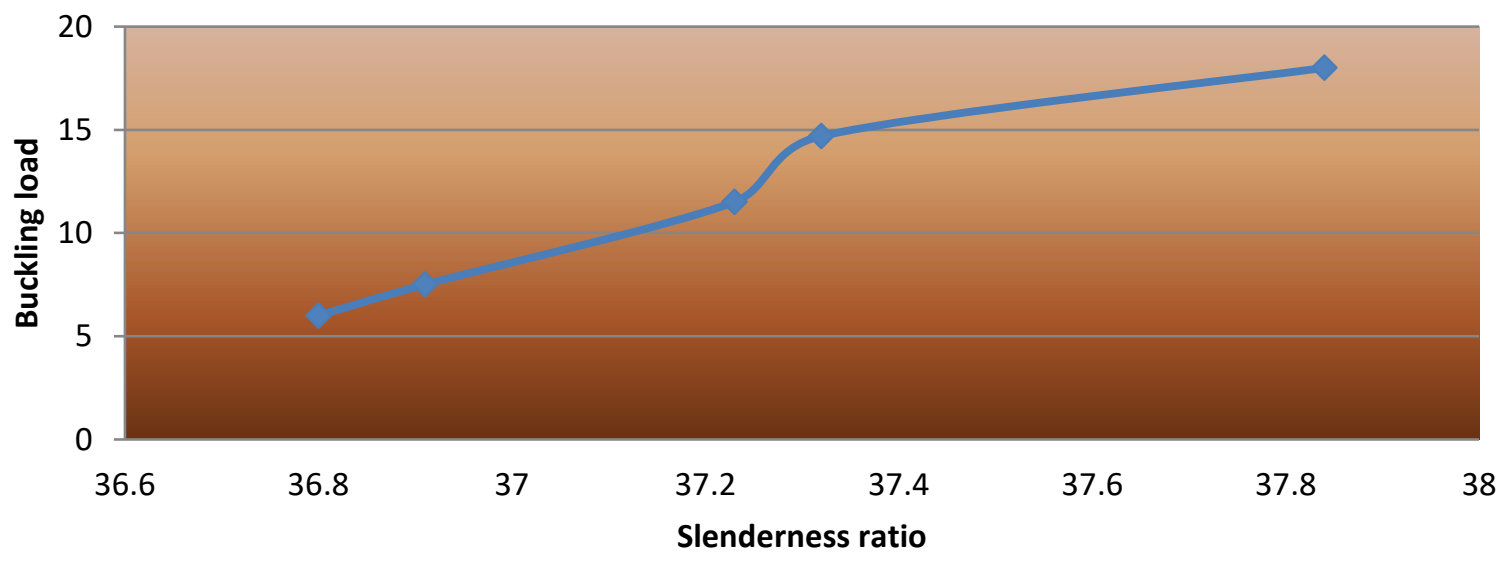

Fig 3C: Graph of buckling load vs. (1/k) ratio of column

As length varies but cross sectional area remains same the buckling load decreases with increase in $(1 / \mathrm{k})$ ratio. But, in this experimental study the case is reverse when cross sectional area increases keeping outside diameter and length constant and varying inner diameter the said load increases with $(1 / \mathrm{k})$ ratio. According to the figure $3 \mathrm{C}$ it is observed that rate of increase of buckling load with respect to increase in slenderness ratio is $1363.6 \%$ when wall thickness is varied from 1.6 to $1.8 \mathrm{~mm}$. Correspondingly, With increase in wall thickness from 1.8 to 2.3 the rate of increase of buckling load with respect to increase in slenderness ratio is $1230.6 \%$, the rate of this increase for 2.3 to 2.9 is 3555.4 $\%$ which is comparatively higherand for thickness 2.9 to 3.3 the rate is $634.6 \%$ i.e. on lower side.
Therefore, from the figure $3 \mathrm{~B}$ and $3 \mathrm{C}$ it can be concluded that as the wallthickness varies from 2.3 to 2.9 the rate of increase of $(1 / \mathrm{k})$ ratio is comparatively lower but rate ofincrease of buckling load with respect to the slenderness ratio is comparatively higher. On the other hand it is observed as wall thickness varies from 2.9 to 3.3 the rate of increase of slenderness ratio is comparativelyhigher but the rate of increase of buckling load with respect to the slenderness ratio is comparatively lower.

The figure 3D shows the curve between the buckling load and the ratio of inner to outer diameter. The graph shows that as the ratio of inner to outer diameter increases the buckling load decreases with slow rate. 


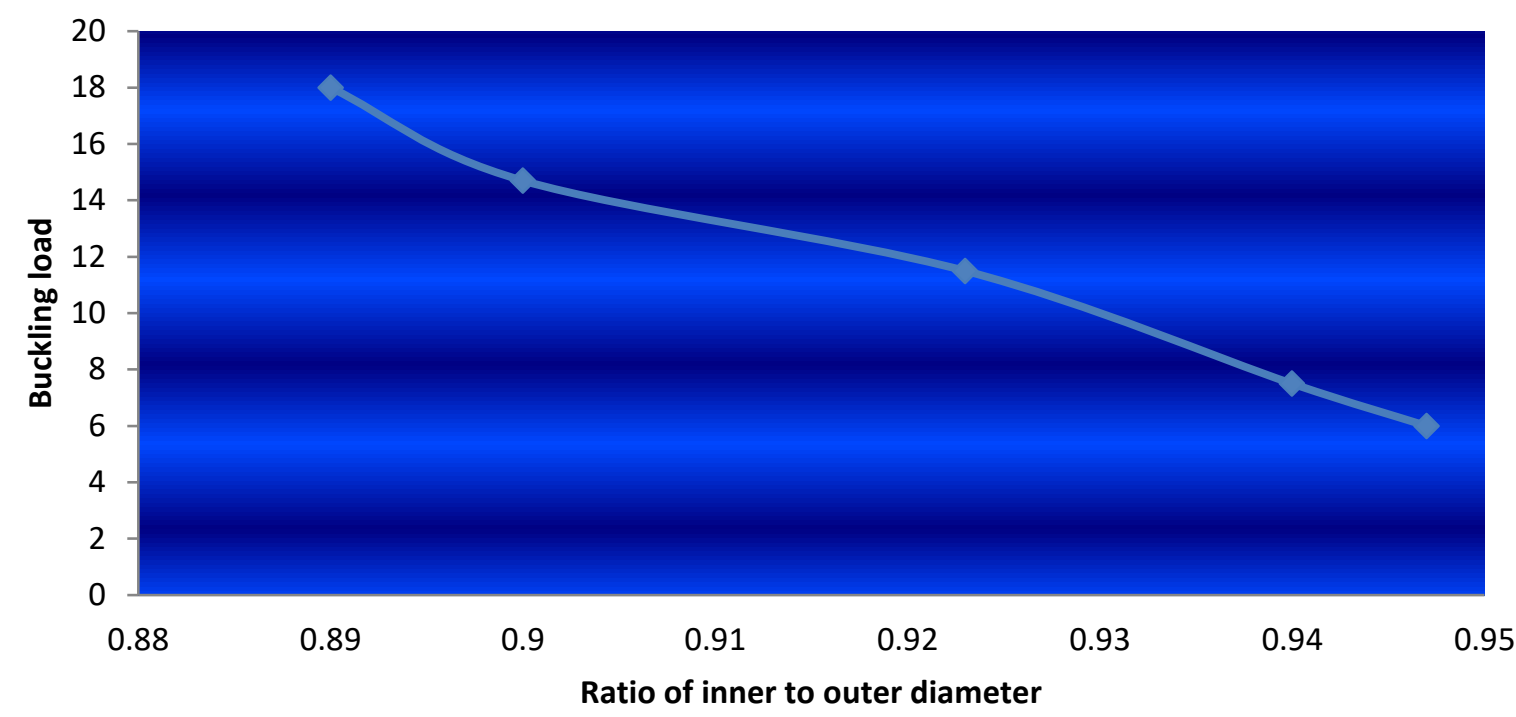

Fig 3D: Buckling load vs. ratio of inner to the outer diameter

As we go through figure 3D given above wall thickness varies from 1.6 to 1.8 the percentage rate of incrementin buckling loadwith respect to decrease in ratio of inner diameter to the outer diameter is $2148.5 \%$. As go through the wall thickness from 1.8 to $2.3 \mathrm{~mm}$ the percentage rate of increment in buckling load with respect to decrease in ratio of inner diameter to the outer diameter is $23529.4 \%$. For wall thickness varying from 2.3 to 2.9 rate of increase is $13913 \%$ and subsequently for wall thickness increment from 2.9 to $3.3 \mathrm{~mm}$ percentage rate of increase of buckling load $33000 \%$. Here, it is observed that the rate of increase is comparatively lower for 2.3 to $2.9 \mathrm{~mm}$ wall thickness and comparatively higher for 2.9 to $3.3 \mathrm{~mm}$.

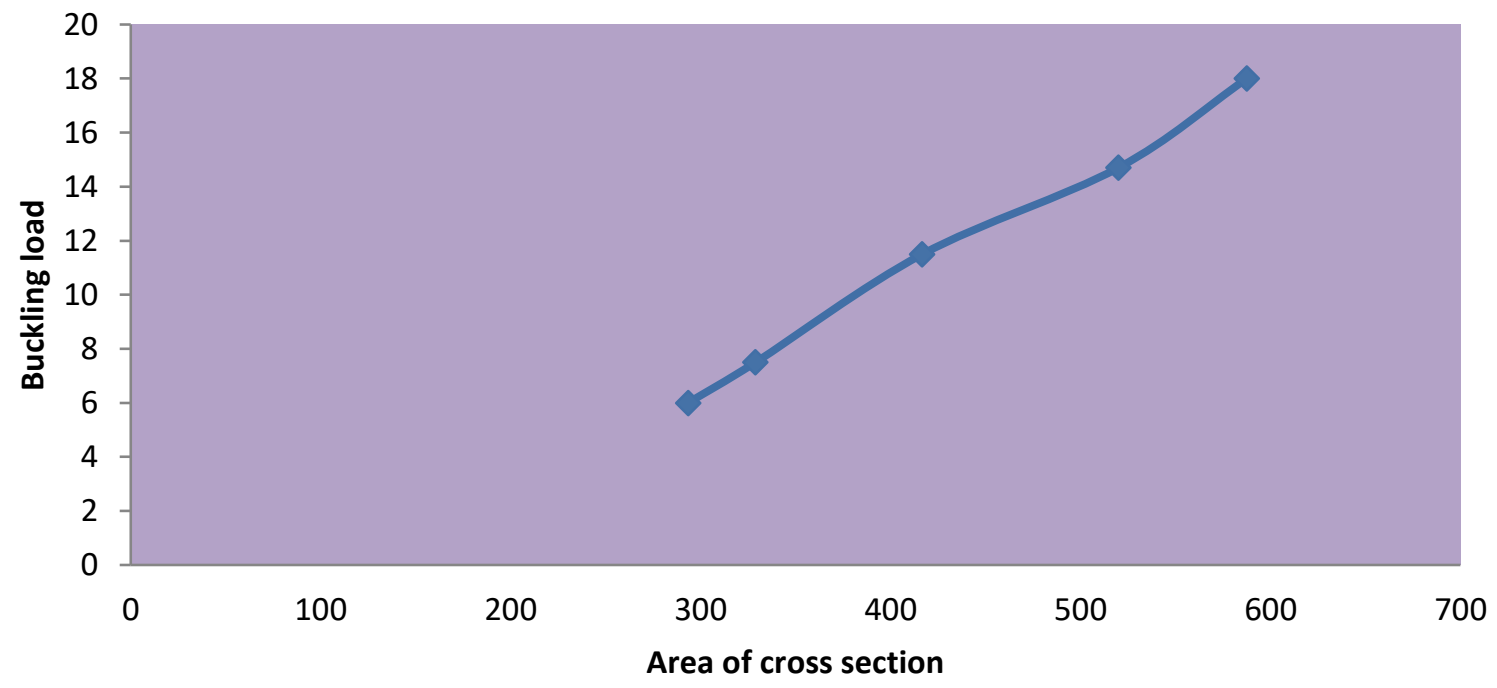

Fig 3E: Buckling load vs. area of cross section

As per depicted figure 3E for the columns of wall thickness of 1.6 and 1.8 the rate of increment of buckling load with increase of cross sectional area is $4.22 \%$, for the column 1.8 and 2.3 the increment rate of buckling load with increase of cross sectional area is $4.56 \%$, for the column of wall thickness 2.3 to 2.9 the rate of increase in buckling load is $3.09 \%$ and the rate of buckling load with increase of cross sectional area is $4.88 \%$ for the column $2.9 \mathrm{~mm}$ and $3.3 \mathrm{~mm}$.

\section{CONCLUSION}

With this study it is concluded that hollow mild steel columns having fix length and outer diameter the bending behavior is good. The radius of gyration decreases with increase in wall thickness and on other hand buckling strength increases as the $(\mathrm{l} / \mathrm{k})$ ratio increases. It has also been observed that the rate of increase of buckling load with respect to ratio of inner to outer diameter is comparatively 
higher for the 2.9 to $3.3 \mathrm{~mm}$ wall thickness and lower for the 2.3 to $2.9 \mathrm{~mm}$. Additionally, for the wall thickness which varies from 2.3 to 2.9 the rate of increase of slenderness ratio is comparatively lower and as thickness varies from 2.9 to 3.3 higher. And also for the wall thickness which varies from 2.9 to 3.3 the rate of increase of slenderness ratio is comparatively higher but the rate of increase of buckling load with respect to the slenderness ratio is lower. These studies may be helpful for structural engineers while designing for erection and installation of any industrial establishment.

\section{ACKNOWLEDGEMENT}

The authors are thankful to CSIR-CIMFR for conducting the experiment.

\section{REFERENCES}

[1]. R.S. Khurmi, S.Chand publication, Strength of Material, pp: 723-736

[2]. Benedict Kriegesmann; Mark W. Hilburgerand Raimund Rolfes; The Effects of Geometric and Loading Imperfections on the Response and Lower-Bound Buckling Load of a Compression-Loaded Cylindrical Shell ;pp:-1

[3]. J. W. Hutchinson ,R. C. Tennyson andD. B.M uggeridge ;Effect of a Local Axisymmetric Imperfection on the Buckling Behavior of a Circular Cylindrical Shell under Axial Compression ;Reprinted/ from AIAA JOURNAL, Vol. 9, No. I, January 1971; pp-1

[4]. Goutam saha and Sajeda Banu; Buckiling load of a beam-column for different end conditions using multi segment integration technique; Vol2, no1 february2007 ;PP: 1-6

[5]. Yoontae Kim, Buckling of a Cracked Cylindrical Shell ReinforcedWith an Elastic Liner, Department of mechsanical and industrial engg. Boston, Maasssachusetts August 2011, pp:-5-7 \&13

[6]. Bassem L. Gendy *, M.T. Hanna; Effect of geometric imperfections on the ultimate moment capacity of coldformed sigma-shape sections; Housing and Building National Research Center HBRC Journal; 23 April 2015; pp-1-2

[7]. Glenn A. Hrinda; Effects of Shell-Buckling Knockdown Factors in Large Cylindrical Shells;NASA Langley Research Center, Hampton, Virginia, 23681; pp-1-2

[8]. J. W. Hutchinson , R. C. Tennyson andD. B.M uggeridge ;Effect of a Local Axisymmetric Imperfection on the Buckling Behavior of a Circular Cylindrical Shell under Axial Compression ;Reprinted/ from AIAA JOURNAL, Vol. 9, No. I, January 1971; pp-1

[9]. Khuram Shahzad, Sagheer Ahmed and Himayat Ullah; NESCOM, Islamabad and MED UET Taxila ; Effect of Geometric Imperfection on Buckling Strength of Cylindrical Shells; pp-1-2

[10]. Mehmet Avcar. Elastic Buckling of Steel Columns under Axial Compression. American Journal of Civil Engineering. Vol. 2, No. 3, 2014, doi: 10.11648/j.ajce.20140203.17; pp- 102-106

[11]. Mohammad Hadi Hajmohammad and Javad Faraji. ; study of effect of geometrical parameter on the buckling of cylindrical shells under hydrostatic pressure; Indian Journal of Science and Technology,vol6(11) ,5527-55332, November 2013

[12]. www.mustan2.com/stability fun; end condition with action and movement; pp;1-3

[13]. W.R .Johnson; study of buckling of conical column; $\mathrm{pp} ; 1-5$

[14]. Johan Bystrom and Leonind Kuzmin ; circular vs. triangular cross section; some thoughts about bending stiffness in 2013 ; pp: $1-4$ 